Chapter 6

\title{
The Use of Behavioral Manipulation Techniques On Synthetic Insecticides Optimization
}

\author{
Solange Maria de França, Mariana Oliveira Breda, \\ Cesar A. Badji and José Vargas de Oliveira
}

Additional information is available at the end of the chapter

http://dx.doi.org/10.5772/53354

\section{Introduction}

The necessity of ever increasing agricultural production has induced farmers to use insecticides to improve yields and profits. The current agricultural mode of production is therefore based on intensive use of insecticides in order to ensure the high productivity by eliminating pests and diseases. Otherwise, others xenobiotics are often used as fertilizer to replace nutrients carried out in agroecosystems. However, in many places, the indiscriminate, prolonged and inappropriate use of these xenobiotics has been affecting the ecosystem and farmers health. Concerning insecticides on agroecosystems, the frequent applications can often cause pest resurgence, environmental pollution and human intoxications, eliminate beneficial insects and enables the emergence of the phenomenon of pest resistance. Under this scenario, the search for other control methods aiming to decrease insecticides use, consequently reducing environmental pollution, the ecological imbalance and human intoxications is required. For this purpose, the understanding of the relationship between the various living organisms in the agroecosystems is essential to provide effective pest control. Living organisms present in the fields of production and its surroundings areas feature between them relationships for survival and preservation. In the specific case of insects, the study of chemical ecology focusing on the intra-and interspecific processes of choice and location of partners, hosts, food sources and shelter have had an important role in the pursuit of a sustainable agriculture. In order to offer more alternatives to control pests, early in the second half of the twentieth century studies were initiated for the development of pest management techniques based on behavioral manipulation of the target organism. When it became clear that insects use their senses to communicate with conspecific and other species of animals or plants, it was possible to 
develop pest behavior research for the benefit of farmers and the environment. What compounds can be used to manipulate the pests and keep them below their level of damage? What behavior can be explored in Integrated Pest Management to reach sustainability in agriculture?

At this current scenario of sustainable development, behavioral control is therefore appropriate by enabling to reduce the use of synthetic insecticides, which usually have broad spectrum and side effects to humans, beneficial insects and environment. Compounds and molecules involved in behavioral pest management such as feeding stimulants and semiochemicals, mostly sex pheromones, can be very useful to reduce synthetic insecticides dosage.

Practical applications of semiochemicals, including the sex pheromones, can lead to modification of pest communication permitting mating disruption, attraction to pint-source lures for monitoring, control by mass trapping, push-pull and attract-and-kill. Attractant lures can also be used for insect population control, in combination with large-capacity traps or a contact insecticide (Witzgall et al. 2008). The idea of controlling insect populations through speciesspecific manipulation of sexual communication, without adversely affecting other organisms, has been a driving force for pheromone research. According to Foster \& Harris (1997) manipulation is defined as the use of stimuli that either stimulates or inhibits a behavior and thereby changes its expression. This has been achieved and technological shortcomings have been overcome through a joint effort between researchers, industry, and growers. Adoption of semiochemical-based pest management has increased in the face of dwindling conventional options, such as insecticides, increased government regulations and improved cost-competitiveness.

There are severals main elements of the behavioral manipulation method on which the tactics and strategies targeting the pest management should be based: knowledge about the behavior of the pest, identification of behaviors that should be handled, the ways in which the behavior is manipulated appropriately and the development of methods and tools that are used in the behavioral management of pests. This chapter will discuss pest monitoring and different behavioral manipulation techniques that can be used alone or in combination with other control methods and enable the optimization of synthetic insecticides use in agriculture.

\section{Monitoring with attractant-baited traps is an important component of pest-management programs}

In the vast majority of farms, pest control is done by spray scheduled. Insecticide applications are made at determined times regardless of the insect population density. When the control by spray scheduled is not used, the presence of a single organism potentially damaging to the culture determines insecticide applications. There is no doubt that those forms of control are not sustainable both environmentally and economically. Therefore, one of the important steps to change those procedures of agricultural production is to quantify the potential damage 
caused by pests. This determination allows knowing if the insects population density found in the crop can be tolerated. For this reason, one of the major uses of monitoring is the determination of early pest incidence; determine if the pest population has reached levels that will cause economic damage; as well as the detection of infested areas; inspection of quarantine pest presence, among other uses.

The Integrated Pest Management (IPM) which recommends the use of control methods when the pest population reaches the Economic Injury Level (EIL) depends on the monitoring for an effective decision making. Pest monitoring is an extremely important tool, for through it, the proper time to use a control method is defined. If the adopted is chemical control, the insecticides application should be done only when the pest population density reaches control level. Thus, monitoring allows defining the spatial and temporal distribution of the insect. This strategy makes pest control more efficient and economic, reducing costs and time sampling, rationalizing sprayings and preserving biodiversity in the agroecosystems. In pest monitoring, several devices, such as traps, can be used spread out in the fields aiming to quantify specific insects. The number of insects measured is important in the decision making for determine whether the pest population has reached the EIL. At this stage of pest management, assessment is, therefore, qualitative. The important in this case is to obtain a correlation between the number of insects measured and its real population density. For monitoring, a large number of tools can be used as beat cloth, trays or traps. In the case of traps, several attractants can be used, such as pheromones, food and attractive colors.

Pheromones are widely used in pest monitoring (Wyatt 1998) due to their specificity, selectivity and mainly for not affecting the health of workers and environment. They are chemicals used in conspecific communication, acting both in physiology, on individuals development; as in behavior, with a domino effect, prompting immediate action. The domino effect is what is explored in pest monitoring. Among the various existing types of pheromones, the sexual is the most widely studied in insect pest management (Vilela \& Della Lucia 2001). The detection and recognition of pheromone molecules by insects are closely related to the olfactory system. The pheromone molecules reach the pores of the antenna sensilla, which are present in the thousands on antenna surface, vertically oriented and capture molecules in the air (Mustaparta 1984). Inside the antenna, the odor molecules collide with the dendritic membrane translating the chemical signal into electrical potential. The nervous impulse is transmitted to the central nervous system to produce a particular behavior in insects. These selective attractants are used in traps spread in the field that are to be monitored. Traps baited with pheromones must be sensitive enough to capture insects selectively, consistently and at low densities. Therefore, the knowledge of the target insect flight behavior is crucial when choosing the type of traps. Trap location and its height in the field, the most appropriate format and the most suitable pheromone mix for the site should be determined from studies of insect reproductive behavior. Additionally, the choice of the trap should be appropriate to the features of the land where the crop is located. Traps which have liquids as surface retention of insects are more difficult to be handled in a land of accentuated incline. In this case, models of traps where the insects are trapped by surfaces impregnated with adhesive glue would be more appropriate. These monitoring tools should be efficient enough to capture the target pest at low population 
densities, be easy to handle and to carry and also should have low cost, high durability and strength. These parameters, which should be determined, are essential for successful monitoring.

The monitoring has been used on many economic important pest worldwide using traps containing pheromone to estimate population density in important crops such as maize and tomato. The reports of its use to estimate populations of Spodoptera frugiperda (Mitchell et al. 1985, Tumlinson et al. 1986), Ostrinia nubilalis (Hudon et al. 1989), Keiferia lycopersicella (Ridgway et al. 1990) and Tuta absoluta (Charlton et al. 1991) shows that this is not a new tool of pest management. However, given the current need for sustainability of agricultural activities, such monitoring proved to be economically viable and environmentally sustainable, by determining the ideal time of interventions to reduce the population of pests in the field.

Besides pheromone use, monitoring can be performed based on visual stimuli. Insects that use vision to locate hosts can be monitored with the aid of colored traps. The principle of this method is to ensure that the insects are lured into a colored surface impregnated with glue. In reference (Natwick et al. 2007) it was recorded the efficacy of colored sticky traps to detect and monitor Frankliniella occidentalis in lettuce. In this particular case, the blue color would be more suitable. Studies have indicated that while there are no insects caught in traps, there is no need to carry out chemical control. The adoption of this monitoring by lettuce growers can reduce insecticide applications in the field. It should be noted that when using visual stimuli, based on color as attractant in traps, the preference of the target insect must be followed.

Food attractants can also be used for monitoring pests. In horticulture, the technique is widely used to monitor fruit flies. In this case, food baits are used in traps to attract insects. Several attractants, such as brown sugar, sucrose, hydrolyzed corn protein, fruit juice and wine vinegar in McPhail, Jackson and PET bottles traps are used for monitoring (Nascimento et al. 2000). One example is the use of orange and grape juices at a concentration of $25 \%$ that are being used in monitoring Anastrepha fraterculus in peach orchards (Guerra et al. 2007).

\section{Mating disruption}

The acceptance of the communication-disruption tactic has largely been driven by dissatisfaction with the control levels achieved with conventional insecticides, often because of emerging resistance problems. Furthermore, in contrast to insecticides, the effectiveness of mating disruption increases with long-term use, resulting in a substantial reduction of populations.

Most of the studies on the use of attractants to disrupt a finding behavior have focused on mate location, particularly of moths, in the so-called mating disruption method. This control method has come to prominence in pest control the last decades. Its success has been observed in 
controlling several pests like the pink bollworrn, Pectinophora gossypiella on cotton; the oriental fruit moth, Grapholita molesta, on stone fruits; tomato borer fruit Neoleucinodes elegantalis, in tomato and codling moth, Cydia pomonella in apple, in which codling moth mating disruption enables sustainable and reliable control at low population densities.

This method consists of distributing a large amount of synthetic sex pheromone in the field, aiming to prevent the male to find a female, disrupting mating. Therefore, new pest generations do not occur on treated area. Nevertheless the success of this method is associated with pest migratory ability and biological aspects. According to reference (Cardé \& Minks 1995) the use of sexual disruption certainly results in success, due to its ability to reduce the local population of the pest. However, it does not protect the area of immigration from outside populations, when used in an isolated way by a single producer or when there is no geographic isolation (geographic barriers). In order to avoid these potential problems, to ensure that this method will obtains the desirable success, it is required a good knowledge about the ecology of the pest and its immigration ability, aiming the entry capacity of mated females, coming from outside the treated area. The sphere of lures influence must be determinate for obtaining the distance between them in the field. Research will focus on determining the number of lures, their dosages and their spatial arrangement to reduce mating success.

The logistics involved in implementing the method, also deserves attention, as it requires an accurate monitoring program, based on samplings with traps baited with pheromone, to determine or even to ensure that the use of disruption is enough to keep the pest population levels under the economic threshold level, thus justifying the method.

\subsection{Mating disruption mechanisms}

The sex pheromone may act through different mechanisms in mating disruption, however, the main behavioral mechanisms have been defined as sensory fatigue by diminution of response due to sensory adaptation or habituation, arrestment of upwind flight at high concentrations, shifting the rhythm of response to females, changing the fine structure of or camouflaging a natural plume, outcompeting females, and causing an imbalance of sensory inputs by altering the perceived blend. In spite of the large amount of work on mating disruption of moths, as well as the considerable volume of work on the actual behavioral mechanisms used by male moths in response to pheromone, behavioral control has not been widely used in pest management (Cardé \& Minks 1995, Foster \& Harris 1997). In this chapter we discuss some of these mechanisms, as follows.

Diminution in responsiveness via either sensory adaptation or habituation: Encounters with formulated pheromone may raise the males response threshold or abolish responsiveness entirely. Either outcome could result from adaptation of peripheral receptors on the antennae or habituation at a central processing level. Continuous release of pheromone formulation, leading to its constant presence in the area, increases habituation.

Shifting the rhythm of response: The continuous presence of pheromone can cause males to respond to formulated pheromone well before females call. Such precocious male activity could contribute to a diminished response when females commence pheromone release. 
Camouflage of the plumes from calling females: At some distance downwind of a moth releasing pheromone, the concentration of pheromone emitted from the moth's odor plume should be rendered imperceptible in a background of synthetic pheromone. At those distances the male would be unable to distinguish the natural plume filaments.

Competition between calling females and point sources of synthetic pheromone: Males may remain responsive and orient to pheromone plumes from point-source release devices. The ratio of dispensers to calling females and their comparative attractiveness will set the intensity of competition. The time spent orienting to artificial point sources of pheromone lessens the time available to orient to plumes from calling females.

\subsection{Dispenser technology}

Practical applications of the mating disruption technique require efficient and economic dispenser materials that release sufficient amounts of pheromone over an extended period. The pheromone dispenser technology determines the efficacy and the economics of mating disruption.

The importance of adequate rate release and consistently for long periods is undisputed in this technique success. That can be observed by several studies testing different release technologies (dispensers), as observed in references (Knight et al. 2012) and (Bohnenblust et al. 2012). As some successful technologies, we mention the sealed polyethylene vials and the SPLAT ${ }^{\circledR}$ Specialized Pheromone \& Lure Aplplication Technology (Figure 1).

Sealed polyethylene vials with pheromone kept the communication disruption for the millet stem borer, Coniesta ignefusalus for up to three months in millet farmers' fields (Youm et al. 2012). SPLAT emitters, which is an emulsion paste (wax) and amorphous that controls the release of insecticides and semiochemical was effective to achieve communication disruption by season-long for several Lepidoptera pests like N. elegantalis in tomato (França et al. in 2012, unpublished data), Bonagota salubricola and G. molesta in peach (Härter et al. 2010, Stelinski et al. 2010) and Phyllocnistis citrella in citrus (Stelinski et al. 2007).

Not only the pheromone dispenser technology, but the amount of dispensers is an important factor for the efficiency of male mating disruption, since it influences the mechanisms involved in this process. The number of pheromone release sites is related to the initial density of the pest, for when the density is high the number of dispensers has to be raised, in order to obtain the effectiveness of the method. Härter et al. (2010) achieved an efficient control of G. molesta in peach, using 1000 release sites (with SPLAT ${ }^{\circledast}$ technology) of pheromone, reducing male catch and the damage from this pest. Pastori et al. (2008) testing 1000 release sites (SPLAT ${ }^{\circledast}$ technology) of B. salubricola pheromone associated with G. molesta pheromone in apple, reduced male catch in both species in the first season. In the following season the catch reduction was only observed for G. molesta, however, it did not reflect in damage reduction. For the millet stem borer, C. ignefusalus suppression of male catch was obtained when the crops were treated with 400 dispensers / ha (Youm et al. 2012). 


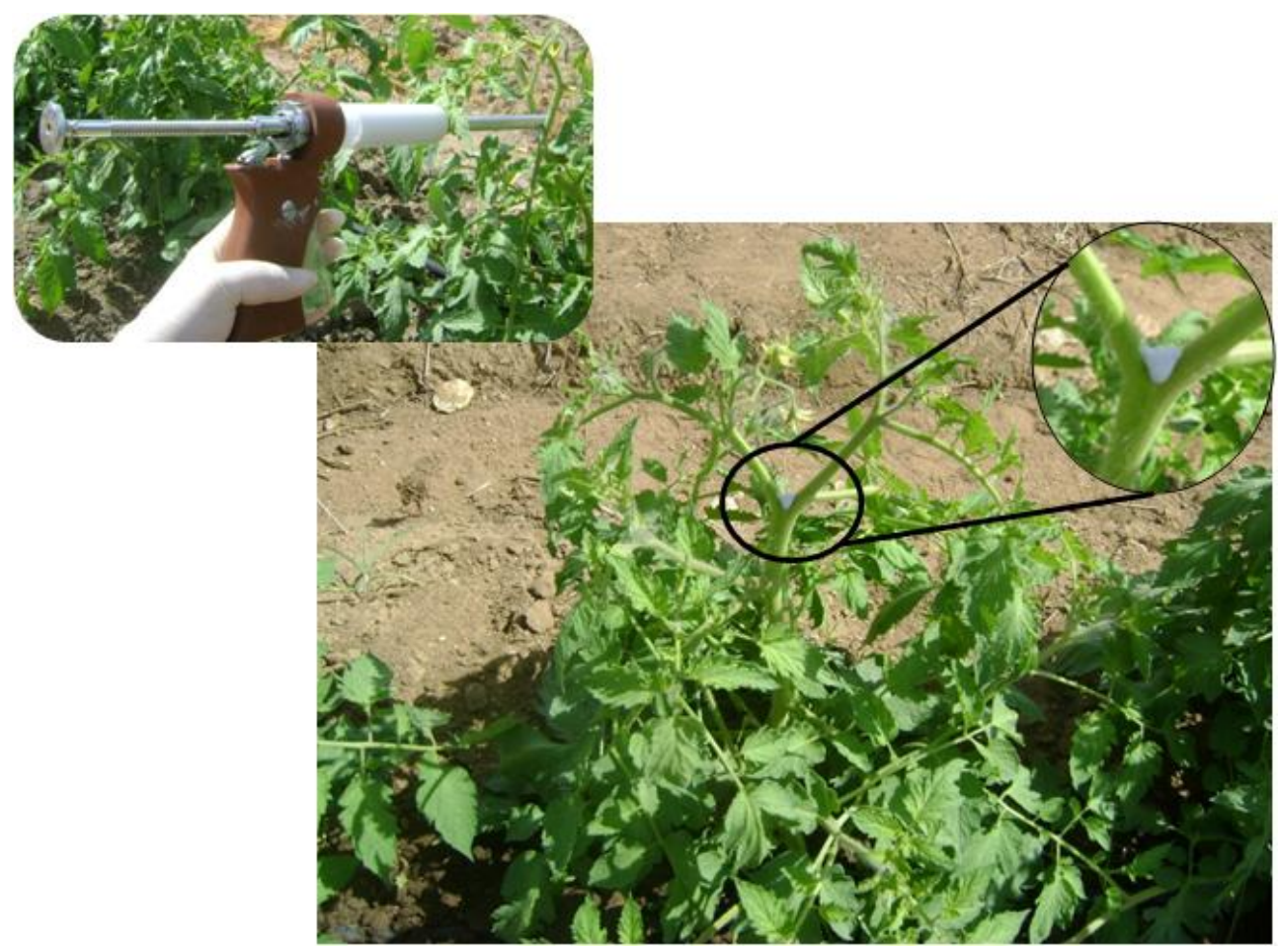

Figure 1. SPLAT NEO (containing Neoleucinodes elegantalis pheromone) on tomato crop in Bezerros, PE. At the top left, the applicator used.

Others technologies have also been used as the microencapsulated formulation. A fortnightly application of the sex pheromone using this technology in peach orchards prevented the chemical communication between the male and female of G. molesta, reducing male catch in traps baited with commercial pheromone. Thus, both the SPLAT ${ }^{\circledR}$ and the microencapsulated pheromone was effective to interrupt the chemical communication of G. molesta in peach orchards, even when this was associated with B. solubricola pheromone (Botton et al. 2005).

\subsection{Association of mating disruption with synthetic insecticides}

An important point is that in several management programs disruptants may need to be used in combination with conventional insecticides, the latter either to reduce initial populations or as an adjuvant to the disruptant. In these cases, a reduction in the use of conventional insecticides is an additional consideration in assessing whether a disruption program is successful (Cardé \& Minks 1995). The use of synthetic insecticides associated with pheromone in order to increase the efficiency of control in some situations (Witzgall et al. 2008) could increase the adoption of this control technique. 
Often the use of this technique reduces the male catch, causing mating disruption, however it does not imply reducing the damage caused by the pest. Probably, this should occur by the entry of mated females originating from untreated areas, so specific applications of insecticides may be indicated to reduce this negative effect. Although, Pastori et al. (2008) reported that using SPLAT ${ }^{\circledR}$ dispensers containing B. salubricola pheromone associated with G. molesta pheromone, with or without cypermethrin in the formulation, found that the presence of the insecticide did not affect the results. Moreover, França et al. (2012) (unpublished data) obtained a greater reduction in both male catch of $N$. elegantalis, oviposition on fruits and damage reduction, when used SPLAT ${ }^{\circledR}$ dispensers containing pheromone associated with cypermethrin compared with SPLAT ${ }^{\circledast}$ containing only pheromone (Figure 2 ). The mating disruption technique led to the same reduction of damage caused by G. molesta in peach orchards, compared with orchards submitted to insecticide spraying, demonstrating the great advantage of using this method (Härter et al. 2010). Therefore, using mating disruption, the number of insecticide applications can be reduced or even absence, making the production environmentally sustainable and economically viable, since the money spent on insecticides can be used in obtaining the product to carry out the disruption. Thus, this tactic is quite appropriate for cultures where no residues of pesticides is required or desired, such as fruits for export; and with the consumer profile in transition, becoming increasingly discerning, the search for an alternative control method is essential to the acceptance and retention of the farmer in the current scenario.

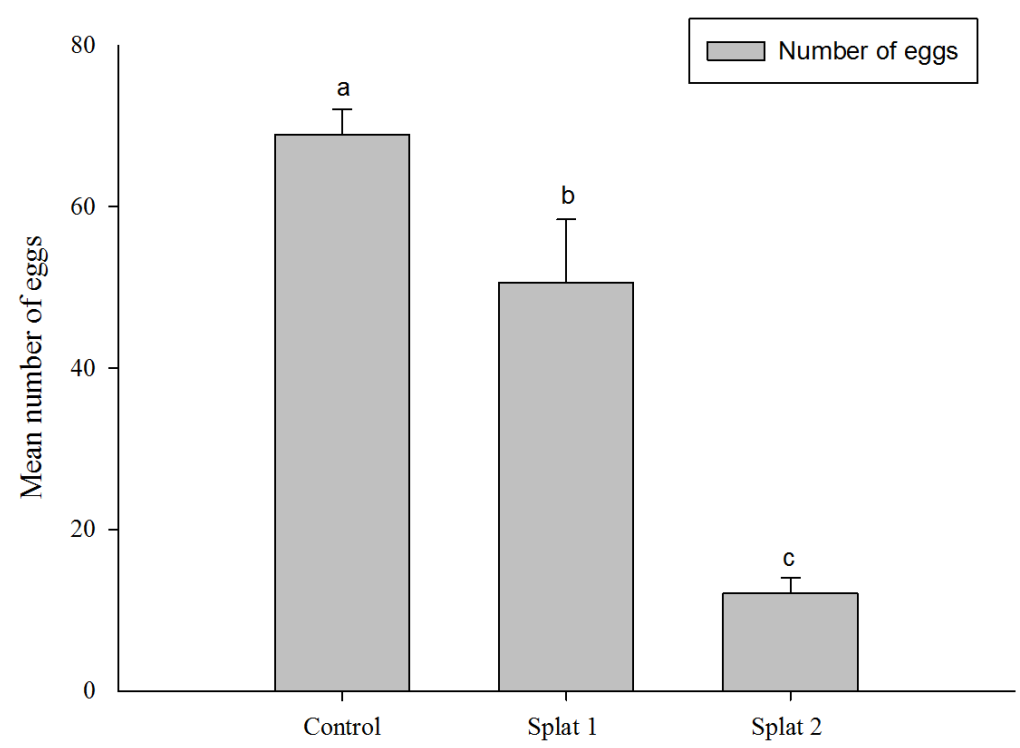

Figure 2. Mean number of $N$. elegantalis eggs throughout tomato crop cycle, variety TY, treated with Splat 1 (with cypermethrin), Splat 2 (without cypermethrin) and control (led by the producer) submitted to treatments 20 and 30 days after transplanting (Camocim de São Félix, Pernambuco, Brazil, 2011-2012). Columns with different letters are significantly different $(p>0.05)$ by Tukey test. 


\section{Attract-and-kill (A\&K) System}

A novel approach using sex pheromones is the attract-and-kill system. This strategy is a new pest management technique, an extension of mating disruption, which is characterized by the inclusion of an insecticide (killing agent) in addition to the pheromone active ingredient or a feeding attractant (attracting agent). By doing this, it is possible to achieve the same control methods as mating disruption, with the potential for increased efficacy, resulting from the toxicity of the insecticide (Ebbinghaus et al. 2001). Unlike mating disruption, which functions by "confusing" the insect, attract-and-kill system attracts the insect to a pesticide laden gel matrix, distributed as small droplets in the crop, which, upon contact, kills the insect.

With this system, blanket coverage of the crop is not necessary, and so the amount of insecticide can be significantly reduced. Such an approach would permit reductions in the amounts of insecticides used and would minimize contact with the environment, the crop, and beneficial organisms. An additional benefit of an attract-and-kill formulation is that these formulations generally require less pheromone to be effective, since the target species does not need to be overwhelmed by the pheromone; it only needs to be attracted to it.

However, when pheromones are used as the attracting agent, only males are killed. Nevertheless, removal of males from a population may not have a significant effect on reproduction unless a large percentage of the male population is killed, as a small percentage of the male population will serve to mate with most sexually receptive females. Thus, the development of an attract-and-kill system might be enhanced with chemical lures that are effective in bringing females into a target. Although the majority of chemical attractants are female-produced sex attractants that lure males, female may use chemical odorants to locate and select mates, host plants and food.

The use of attract-and-kill suffers from some of the same constraints as mating disruption, including the high degree of pest selectivity, a reduction in efficacy with increasing pest density and risk of immigration of mated females. Besides, the different longevity in the insecticide activity and the attractiveness of the droplets set a time-limit for the application. The attractand-kill drops often deteriorated quite rapidly under some weather conditions, such as powerful storms, pelting rain, intense heat, and solar radiation. These conditions may affect the stability and longevity of the system.

As with any management tool, the operational use of pheromones must be considered within the context of an integrated pest management system. Commercialization of the attract-andkill approach has been undertaken by IPM Technologies Inc., who has global rights to a proprietary and patented matrix, combining insecticide and attractant in a UV sensitive carrier material. Marketed as "Sirene ${ }^{\mathrm{TM}}$ " and "Last-Call ${ }^{\mathrm{TM}}$ " in Europe and the U.S., respectively, this technology was granted US EPA registration in 1998 and California registration in 1999. The robust matrix can accept, protect and release a wide variety of chemicals (acetates, alcohols, aldehydes) so it has the potential to be deployed against many pest species in diverse ecosystems. 
Attract-and-kill systems are more powerful than other semiochemical mediated control strategies such as mating disruption in that male moths are incapacitated and removed from the ecosystem. Yet, this approach has the obvious advantage of limiting any potential negative ecological effects of the insecticide, as only those insects coming to the lure will be affected. These systems has been successfully used against several pests, including the boll weevil, Anthonomus grandis; codling moth, C. pomonella (Charmillot et al. 2000) and apple maggot, Rhagoletis pomonella (Bostanian \& Racette 2001), oriental fruit moth, G. molesta (Evenden \& Mclaughlin 2004), among others.

In fruit production, the fruit flies control is based on the use of insecticides in total coverage or in the form of toxic lure. The toxic lure is based on the use of food bait associated with an insecticide. In this attract-and-kill system, the insects are killed when in contact or ingest the insecticide. Spinosad baits containing spinosad in different concentrations, water, sugar and attractants were effective in controlling the fruit fly, Ceratitis capitata and Anastrepha fraterculus (Raga \& Sato 2005). The formulation SPLAT ${ }^{\circledR}$, afore mentioned at mating disruption, is also used in attract-and-kill system, since its formulation consisting of waxes and oils and allows the inclusion of a wide range of insecticides and attractants with potential to control several species of fruit flies. SPLAT ${ }^{\circledR}$ system has been evaluated as a strategy to attract-and-kill for fruit flies Bactrocera dorsalis and Bactrocera cucurbitae in the United States with promising results (Vargas et al. 2008, Vargas et al. 2009). There are some reports in the literature of a SPLAT ${ }^{\circledR}$ formulation containing spinosad $0.10 \%$, which provided control of C. capitata adult, even after submitted to simulated rainfall, and showed a smaller effect on the parasitoid Diachasmimorpha longicaudata compared with other toxic baits (Zanardi 2011).

Although this method presents the advantage of causing less impact on non-target organisms, some restrictions are observed, for example, the low persistence of toxic lures after rainfall events, as can be seen in the example cited above. These barriers are being solved with the advancement of research on this technology.

Mating disruption and attract-and-kill are similar technologies that have been used to control a wide range of insect pests, typically species in Lepidoptera, Coleoptera, and Diptera (El-Sayed et al. 2006). These two technologies may be able to contribute to the eradication of new incursions of invasive species, because like other inversely densitydependent approaches, they have the greatest probability of success against pests at very low density, which is initially the case after an incursion. Making clear the difference between these control systems, the mating disruption relies on the principle of preventing pheromone communication between sexes, but the insects remain alive in this area during the disruption, whereas in attract-and-kill systems they are removed from the population. Besides, attract-and-kill systems for field control typically use insecticides, while in disruption, insecticides may be used but they are not the primary approach of the system. 


\section{The push-pull strategy}

Insects control methods exploiting natural chemical messengers, collectively known as semiochemicals, are becoming increasingly familiar. Semiochemicals are substances that, in their natural context, carry information or chemical cues for a given interaction between organisms, triggering a behavior or a physiological response in the receiving individual. They are subdivided into allelochemicals, related to interspecific communications, and pheromones, in intraspecific communications (Vilela \& Della Lucia 2001). One major developments now set to revolutionize the use of semiochemicals is the realization that semiochemicals should not be used alone, but be combined with population-reducing agents such as highly selective pesticides or biological control agents.

Thus, it is rare for a single semiochemical to be very effective when used alone. Instead, the usual approach is a 'push-pull' strategy, also called stimulo-deterrent diversion - which involves 'pushing' the insects away from the harvestable, economic crops, and 'pulling' them onto a trap crop where their population is reduced by a biological control agent or highly specific but slow-acting insecticide (Foster \& Harris 1997). Therefore, antifeedants, non-host volatiles, compounds associated with plant defense, visual cues, synthetic repellents, alarm pheromones and oviposition deterrents can be used to achieve the 'push', while the sex pheromone, host volatiles, visual, gustatory and oviposition stimulants can be used to 'pull' the insects onto the trap crop (Figure 3).

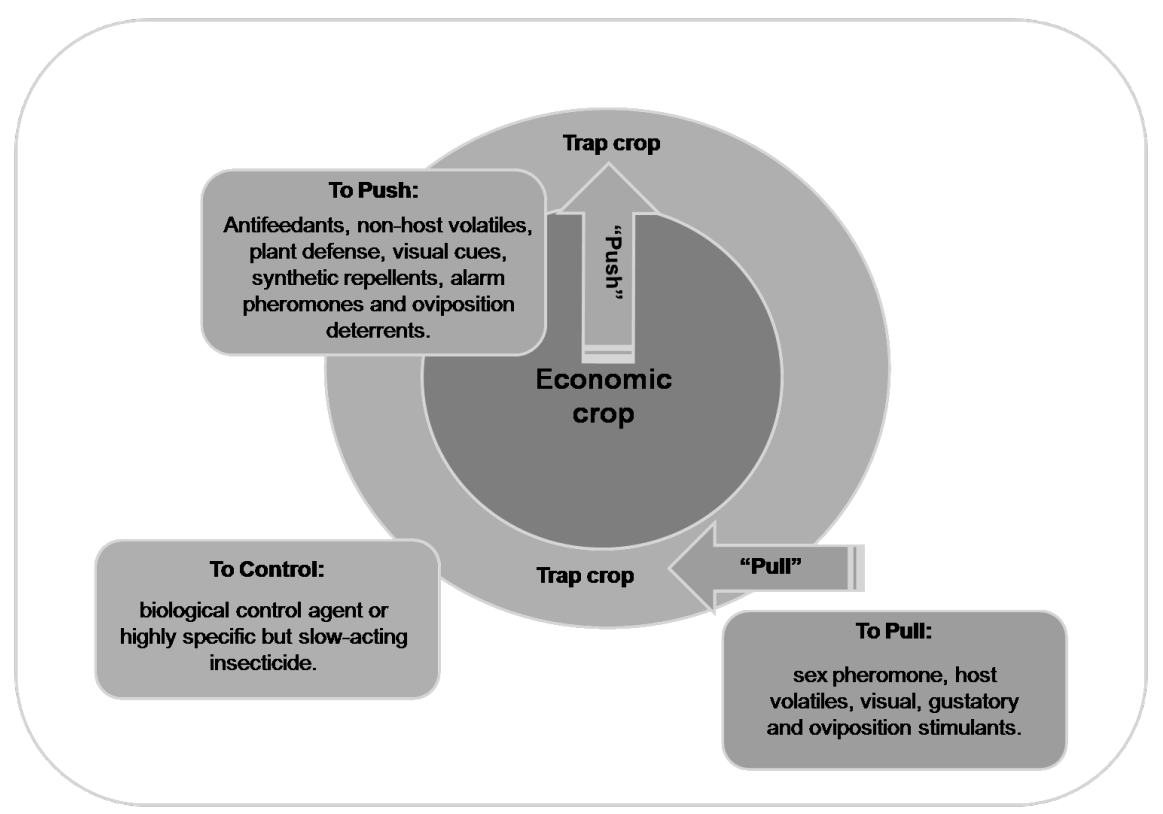

Figure 3. Push-Pull strategies, "pull" and "push" tools and the agents used to reduce pest population. 
The olfactory, visual and mechanical stimuli are used by insects to locate and select their hosts. The ones acting at long distance are visual, synthetic repellents, host and non-host plant volatiles, anti-aggregation and alarm pheromones. At short distance, they are called anti-food, oviposition inhibitor and pheromone inhibitor. This technique has been used for a small number of insect pests and needs to be further investigated.

The term push-pull was first conceived as a strategy for insect pest management (IPM) by Pyke et al. in Australia in 1987. The concept was later formalized and refined by Miller \& Cowles, who termed the strategy stimulo-deterrent diversion. Most work on push-pull strategies has targeted pest behavior rather than to the manipulation of beneficial organisms. However, it may act to push the beneficial organisms out of the surrounding area and pull them to where they are required for control.

The Push-pull strategies can bring together several pest management tactics, as behavioral manipulation methods, chemical stimuli, habitat diversification strategies (intercropping and trap cropping), biological control and chemical control. According to Cook et al. (2007) the principles of the push-pull strategy are to maximize control efficacy, efficiency, sustainability and output, while minimizing negative environmental effects.

\subsection{The use of push-pull}

The Push-pull strategy successfully controls pests and weeds. The most successful push-pull strategy, indeed the only example currently used in practice, was developed in Africa for subsistence farmers. In Eastern Africa, push-pull works as a novel cropping system developed by the International Centre of Insect Physiology and Ecology (ICIPE) in collaboration with Rothamsted Research (UK), Kenyan Agricultural Research Institute (KARI) and other national partners for integrated pest, weed and soil management in cereal-livestock-based farming systems (Cook et al.2007, Hassanali et al. 2008, Khan et al. 2008).

Millions of rural people in Eastern Africa depend on maize and sorghum for food security and cash income. Despite this, production of these crops is seriously affected by constraints such as stemborers and the parasitic weed Striga hermonthica (Nielsen 2001). The push-pull strategy involves the use of behavior-modifying stimuli to manipulate the distribution and abundance of stemborers and beneficial insects in maize or sorghum crops. It is based on in-depth understanding of chemical ecology, agrobiodiversity, plant-plant and insect-plant interactions, and involves intercropping a cereal crop with a repellent intercrop such as Molasses grass (Melinis minutiflora) and Desmodium (Desmodium uncinatum) (push), with an attractive trap plant such as Napier grass (Pennisetum purpureum) and Sudan grass (Sorghum vulgare var. sudanense) (pull) planted as a border crop around this intercrop.

Mated stemborer females are repelled from the main crop and are simultaneously attracted to the trap crop. Napier grass produces significantly higher levels of attractive volatile compounds (green leaf volatiles), cues used by stemborer females to locate host plants, than maize or sorghum (Khan et al. 2001). However, many of the stemborer larvae, about $80 \%$, do not survive as Napier grass tissues produce sticky sap in response to feeding by the larvae which traps them causing their mortality (Midega et al. 2006). Legumes in the Desmodium genus, on 
the other hand produce repellent volatile chemicals that push away the stemborer moths. Desmodium sp. also controls $S$. hermonthica trough an allelopathic effect of the root exudates, produced independently of the presence of the weed, being responsible for a dramatic weed reduction in an intercrop with maize (Khan et al. 2002).

Besides this, the push-pull strategy has been studied for controlling several pests, as for example, Helicoverpa sp. in cotton, the Colorado potato beetle in potatoes, Sitona lineatus in beans, the pollen beetle in oilseed rape, onion maggot on onions, thrips on chrysanthemums, in forestry as the bark beetles on conifers, for veterinary and medical pests as muscid flies, mosquitoes and midges and for controlling urban pests such as cockroaches.

\subsection{Push-pull strategy and insecticides}

According to Cook et al. (2007) the stimuli used to achieve the push-pull strategy generally act by nontoxic mechanisms, thus, integration with population-reducing methods, such insecticides, is also usually needed when the strategies are targeted at pests. The pushpull strategy can be used to displace pests from resources or commodities that are to be protected, and simultaneously lure the pest to an attractant source coupled with an insecticide. In addition, push-pull strategies are beginning to be seriously considered as plausible pest control solutions that help to manage insecticide resistance threats. One study assessing the effects of push-pull strategy with trap crops, neem and Nuclear Ployhedrosis Virus (NPV) in Helicoverpa armigera insecticide resistance on cotton, reported that the push-pull strategy was highly effective in reducing the incidence of $H$. armigera and damage (Duraimurugan \& Regupathy 2005).

The benefits of a push-pull strategy include a lower requirement for broad spectrum pesticides, saving these valuable materials for a 'fire fighting' role. In addition, there is less risk of producing populations of resistant insects. Because the push-pull components are not individually greatly effective, they do not select for resistance as strongly as conventional toxicant insecticides.

\section{Mass trapping}

The knowledge of life history traits of the target insect pest is particularly important to determine if this technique can be used. The behavior of the insect in the search of partners or food should be studied to maximize the chances of success in using this strategy. The mass trapping consists of placing a large number of traps with attractants in a crop in order to capture the largest possible number of insects.

The purpose is to reduce the number of individuals of the next generation, removing only males or both insect sexes of the area. As bait, sexual or aggregation pheromones, food attractants or volatile can be used. The density and effectiveness of traps are important factors for the success of population suppression and eradication technique (Steiner 1952).The technique is particularly effective when it aims to control insects with gregarious habits. In 
these cases, adding a synergist, enhances the capture of both males and females. When using only the sexual pheromones in this technique, generally, only males are caught. The male removal from the area may not have a major impact on the size of the next generation depending on the reproductive biology of the species.

The results achieved with mass collection may not be suitable for pest control as, depending on the mating ability of the species, a single male can fertilize many females, thus preventing the elimination or reduction of the number of individuals of the next generation. To work around this, a combination of pheromone with a food attractant could lead to both males and females catch. The initial size of population should then be estimated by monitoring, before the use of mass collection technique. El-Sayed et al. (2006) indicate the technique for controlling populations at low density or sparsely isolated. In the absence of these conditions, it should not be used alone for pest control. When adults of both sexes are considered pests and in the presence of aggregation pheromone, the technique proves to be effective. Several examples can be found using this technique in agricultural pest control, as in the case of C. pomonella in Europe and America (Hagley, 1978, Willson \& Trammel 1980, Emel'yanov \& Bulyginskaya 1999, Beers et al. 2003), borer of the genus Rhynchophorus in Asia, Middle Eastern and South America; fruit flies in orchards; A. grandis in the United States of America and Mexico; Lymantria dispar in USA, among others.

The results indicate that the success in suppressing pest population and damage reduction is not always ensured, especially when the pest is found in high population density. Some requirements must be observed according El-Sayed et al. (2006) to succeed in using the mass collection. The first is the arrangement of traps in the area, so that a large part of the population has contact with the attractive. The second requirement is that the attractive has to be more effective than the natural source of attraction, as virgin females, foods, among others. This attractive must have an effective release, ranging from emergency to the insect mating season. Traps effectiveness in capture and retention of insects must be observed as well as the cost of the technique.

The mass trapping, when is not enough by itself to control pest population, can be used in combination with other methods of pest control within the philosophy of Integrated Pest Management.

\section{Attractive lures and toxic lures}

Another aspect of behavioral control is the use of secondary plant substances that play an important role in the feeding of monophagous or oligophagous insects (Cohen 2003). These substances are used in insect behavioral and biology studies, such as attraction / repellence, feeding and oviposition deterrence etc (Martinez \& Van Emden 2001). Such chemicals that indicate the presence of food are in many cases, secondary compounds that stimulate chemoreceptor cells located in taste sensilla across tarsi, antennas and mouth parts of insects, inducing feeding and oviposition. When these compounds induce feeding are called phagostimulants or feeding stimulants (Nation 2002). 
Attractive food lures containing feeding stimulants make pest management by behavior manipulation an effective tool, helping to reduce the amount and improve pesticides efficiency applied in agricultural production systems. These attractive lures have been used for the following purposes: (i) identification and distribution of insect species, (ii) certification of a region or country for the absence of a particular pest species (free area), (iii) pest eradication programs, (iv) Integrated Management Program, (v) pest monitoring (Nascimento et al. 2000).

For a higher persistence of phagostimulants at the lures, the starch can be used as a vehicle of feeding stimulant, for example, in combination with insecticides and dry bran. Several attractive, such as brown sugar, sucrose, hydrolyzed corn protein, fruit juice and wine vinegar in McPhail, Jackson and PET bottles traps are used for monitoring, and when added to insecticides are recommended for pest control, as example the fruit flies (Nascimento et al. 2000), contributing to the reduction of pest population in the field. Orange and grape juices at a concentration of $25 \%$ have been used in monitoring $A$. fraterculus in peach orchards (Guerra et al. 2007).

The attraction of Mocis latipes for sweet baits in traps has been studied by Landolt (1995) showing that honey solutions in water $(20 \%)$ or unrefined sugar in water $(5,10$ or $20 \%)$ caught a significant number of moths. This author also found that these baits prepared with three days in advance were more effective than baits made with fresh solutions.

Lures prepared with different concentrations of spinosad insecticide have been effective in fruit flies control, C. capitata and A. fraterculus (Raga \& Sato 2005). Toxic lures formulated with hydrolyzed protein, consisting of Biofruit 3\% plus malathion (500 Malathion EC) applied on plants located at the orchard edges has been effective in controlling $A$. fraterculus on peach trees. However, this practice is not employed by peaches producers, as it requires changes in the pest management system, replacing scheduled insecticides applications for monitoring implementation (Härter et al. 2010).

Toxic lures has also been shown important in the management of lepidopteran pests. According to França et al. (2009) the mortality caused by lufenuron and deltamethrin, associated with $10 \%$ honey, increased directly with the evaluation periods $(0,0.5,1,2,12$ and 24) for males, females and adults of N. elegantalis after exposure to $10 \%$ honey attractive solution, achieving $100 \%$ of mortality in two hours.

One of the advantages of toxic lures is the environmental benefit, since they are not used in the total field area, compared with synthetic insecticides. So, it would provide reduced risk due to the decreased presence of toxic residues in fruits, decreased resurgence of secondary pests, reduction in the amount of insecticides and higher preservation of natural enemies. The use of toxic lure in guava orchards, Psidium guajava, had lower influence on adults of Chrysopidae family, compared to synthetic insecticides application (Galli et al. 2004).

The great success of behavioral management is the ability to associate technologies to control pests, rationing insecticides use, due to applications based on monitoring. The techniques of behavioral control consort with other control methods such as conventional, and benefit not only the consumers but the ecosystem and all involved in the productive chain of agricultural products. 


\section{New trends and conclusions}

Recent studies have shown that an alternative to improve the pheromone performance on male catch is the use of volatile compounds of plants. Tests at wind-tunnel, demonstrated that the volatile compounds of plants, such as limonene, pear ester, $ß$-farnesene and linalool increased the attraction of codling moth males, C. pomonella, when associated with codlemone pheromone also proving that these volatiles not only increase the attractiveness, but also decrease (shorten) the response time of the males to codlemone (Schmera \& Guerin 2012). Thus, based on these observations, it is concluded that admixing limonene, pear ester, $\beta$-farnesene or linalool to codlemone aids source location by males, such that host plant volatiles dispensed with codlemone should contribute to better mating disruption of $C$. pomonella. These authors also state that the attractiveness increasing of codlemone to codling moth males can be regarded as a key to increasing the efficiency of mating disruption of codling moth.

The public demand for environmentally correct alternatives to broad-spectrum insecticides or strategies that reduce the use of these pesticides has never been greater. The adoption of behavioral manipulation techniques can help to meet this demand, since the amount of semiochemicals released into the environment is relatively small. In addition, most of the semiochemicals are relatively nontoxic to vertebrates as well as to beneficial insects, having a high selectivity to the target pest species.

\section{Author details}

Solange Maria de França ${ }^{1}$, Mariana Oliveira Breda ${ }^{1}$, Cesar A. Badji ${ }^{2}$ and José Vargas de Oliveira ${ }^{3}$

*Address all correspondence to: solangeufrpe@yahoo.com.br

1 Graduate Program in Agricultural Entomology, Department of Agronomy, Recife, Pernambuco, Brazil, Universidade Federal Rural de Pernambuco, Brazil

2 Universidade Federal Rural de Pernambuco, Academic Unit of Garanhuns, PE, Brazil

3 Universidade Federal Rural de Pernambuco, Department of Agronomy, Recife, Pernambuco, Brazil

\section{References}

[1] Beers EH, Suckling DM, Prokopy RJ, Avilla J. Ecology and management of apple arthropod pests, In: Feree DC, Warrington I editors. Apples: botany, production and uses. Wallingford, United Kingdom: CABI Publishing; 2003. p489-519. 
[2] Bohnenblust E, Hull LA, Krawczyk G. A comparison of various mating disruption technologies for control of two internally feeding Lepidoptera in apples. Entomologia Experimentalis et Applicata 2012; 138 (3): 202-211.

[3] Bostanian NJ, Racette G. Attract and kill, an effective technique to manage apple maggot, Rhagoletis pomonella (Diptera: Tehpritidae) in high density Quebec apple orchards. Phytoprotection 2001; 82 (1): 25-34.

[4] Botton M, Kulcheski F, Collena VD, Arioli CJ, Pastori PL. Avaliação do uso do feromônio de confundimento no controle de Grapholita molesta (Lepidoptera: Tortricidae) em pomares de pessegueiro. Idesia 2005; 23: 43-50

[5] Cardé, RT, Minks AK. Control of moth pests by mating disruption: success and constraints. Annual Review of Entomology 1995; 40: 559-585.

[6] Charlton RE, Wyman JA, McLaughlin JR, Du JW, Roelofs WL. Identification of sex pheromone of tomato pinworm, Keiferia lycopersicella (Wals.) Journal of Chemical Ecology 1991; 17(1): 175-183.

[7] Charmillot PJ, Hofer D, Pasquier D. Attract and kill: a new method for control of the codling moth Cydia pomonella. Entomologia Experimentalis et Applicata 2000; 94(2): 211-216.

[8] Cohen AC. Insect diets: Science and technology. Washington: CRC Press; 2003.

[9] Cook SM, Khan ZR, Pickett JA. The use of push-pull strategies in integrated pest management. Annual Review of Entomology 2007; 52: 375-400.

[10] Duraimurugan P, Regupathy A. Push-pull Strategy with Trap Crops, Neem and Nuclear Polyhedrosis Virus for Insecticide Resistance Management in Helicoverpa armigera (Hubner) in Cotton. American Journal of Applied Sciences 2005; 2(6): 1042-1048.

[11] Ebbinghaus D, Losel PM, Romeis J, Cianciulli-Teller MG, Leusch H, Olszak R, Pluciennik Z, Schekenbeck J. Appeal: efficacy and mode of action of attract and kill for codling moth control. IOBC wprs Bulletin 2001; 24(2): 95-99.

[12] El-Sayed AM, Suckling DM, Wearing CH, Byers JA. Potential of mass trapping for long-term pest management and eradication of invasive species. Journal of Economic Entomology 2006; 99(5): 1550-1564.

[13] Emel'yanov VA, Bulyginskaya MA. Use of pheromones for control of codling moth Laspeyresia pomonella L. (Lepidoptera, Tortricidae) by elimination and disorientation of males. Entomological Review 1999; 79: 539-546.

[14] Evenden ML, Mclaughlin JR. Initial development of an attracticide formulation against the Oriental fruit moth Grapholita molesta (Lepidoptera: Tortricidae). Environmental Entomology 2004; 33(2): 213-220.

[15] Foster SP, Harris MO. Behavioral manipulation methods for insect pest-management. Annual Review of Entomology 1997 42: 123-46. 
[16] França SM, Oliveira JV, Picanço MP, Lôbo AP, Silva EM, Gontijo PC. Seleção de atrativos alimentares e toxicidade de inseticidas para o manejo da broca-pequena-do-tomateiro. Pesquisa Agropecuária Brasileira 2009; 44(6): 561-568.

[17] Galli JC, Senô KCA, Cividanes FJ. Dinâmica populacional de crisopídeos (Neuroptera: Chrysopidae) associados a pomares de goiaba Psidium guajava L. com dois sistemas de pulverizações de fenthion. Boletín de sanidad vegetal. Plagas. 2004; 30: 197-202.

[18] Guerra DS, Marodin GAB, Zanini CLD, Argenta F, Graselli V, Nunes JLS. Utilização de pesticidas na produção de pêssegos 'marli', nos sistemas de produção integrada e convencional. Revista Brasileira de Fruticultura 2007 29: 091-095.

[19] Hagley EAC. Sex pheromones and suppression of the codling moth (Lepidoptera: Olethreutidae). Canadian Entomologist. 1978; 110: 781-783.

[20] Härter WR, Grützmacher AD, Nava DE, Goncalves RS, Botton M. Isca tóxica e disrupção sexual no controle da mosca-da-fruta sul-americana e da mariposa-oriental em pessegueiro. Pesquisa Agropecuária Brasileira 2010; 45(3): 229-235.

[21] Hassanali A, Herren H, Khan ZR, Pickett JA, Woodcock CM. Integrated pest management: the push-pull approach for controlling insect pests and weeds of cereals, and its potential for other agricultural systems including animal husbandry. Philosophical Transactions of the Royal Society of London 2008; 363(1491): 611-621.

[22] Hudon M, Leroux EJ, Harcourt DG. Seventy years of European corn borer Ostrinia nubilalis research in North America. Agricultural Zoology Reviews 1989; 3:53 -96.

[23] Khan ZR, Amudavi DM, Midega CAO, Wanyama JM, Pickett JA. Farmers' perceptions of a 'push-pull' technology for control of cereal stemborers and Striga weed in Western Kenya. Crop Protection 2008; 27:(6) 976-987.

[24] Khan ZR, Hassanali A, Overholt W, Khamis TM, Hooper AM, Pickett AJ, Wadhams LJ, Woodcock CM. Control of witchweed Striga hermonthica by intercropping with Desmodium spp., and the mechanism defined as allelopathic. Journal of Chemical Ecology 2002; 28(9): 1871-1885.

[25] Khan ZR, Pickett JA, Wadhams LJ, Muyekho F. Habitat management strategies for the control of cereal stemborers and Striga in maize in Kenya. Insect Science and its Application 2001; 21:375-380.

[26] Knight AL, Stelinski LL, Hebert V, Gut L, Light D, Brunne J. Evaluation of novel semiochemical dispensers simultaneously releasing pear ester and sex pheromone for mating disruption of codling moth (Lepidoptera: Tortricidae). Journal of Applied Entomology 2012; 136: 79-86.

[27] Landolt PJ. Attraction of Mocis latipes (Lepidoptera: Noctuidae) to sweet baits in traps. Florida Entomologist. 1995; 78(3):523-530. 
[28] Martinez SS, Van Emden HF. Growth disruption, abnormalities and mortality of Spodoptera littoralis (Boisduval) (Lepidoptera: Noctuidae) caused by Azadirachtin. Neotroprical Entomology. 2001; 30(1):113-124.

[29] Midega CAO, Khan ZR, Van den Berg J, Ogol CKPO, Picket JA, Wadhams LJ. Maize stemborer predator activity under 'push-pull' system and Bt-maize: a potential component in managing Bt resistance. International journal of pest management 2006; 52(1):1-10.

[30] Mitchell ER, Tumlinson, JH, Mcneil JN. Field evaluation of commercial pheromone formulations and traps using a more effective sex pheromone blend for the fall armyworm (Lepidoptera: Noctuidae). Journal Economy of Entomology 1985; 78(6): 1364-1369.

[31] Mustaparta H. Olfaction. In: Bell WJ, Cardé RT. (Editoress.). Chemical ecology of insects. London and New York: Chapman and Hall, 1984.

[32] Nascimento AS, Carvalho RS, Malavasi A. Monitoramento populacional, In: Malavasi A, Zucchi RA. (ed) Moscas-das-frutas de importância econômica no Brasil: Conhecimento Básico e Aplicado. Ribeirão Preto: Holos, 2000. p109-112.

[33] Nation JL. Nutrition. In: Nation JL. Insect physiology and biochemistry. CRC Press: New York; 2002. P65-87.

[34] Natwick ET, Byers JA, Chu CC, Lopez M, Henneberry TJ. Early Detection and Mass Trapping of Frankliniella occidentalis and Thrips tabaci in Vegetable Crops. Southwestern Entomologist, 2007; 32 (4):229-238.

[35] Nielsen, F. The Push-Pull system - a viable alternative to Bt maize. LEISA Magazine 2001; 17(4): 17-18.

[36] Pastori PL, Arioli CJ, Botton M, Monteiro LB, Mafra-Neto A. Avaliação da técnica de disrupção sexual utilizando emissores SPLAT visando ao controle de Bonagota salubricola (Meyrick) e Grapholita molesta (Busck) (Lepidóptera: Tortricidae) na pré-colheita de maçãs da cultivar 'Fuji'. Bioassay 2008; 3(1): 1-8.

[37] Raga A, Sato ME. Effect of spinosad bait against Ceratitis capitata (Wied.) and Anastrepha fraterculus (Wied.) (Diptera: Tephritidae) in laboratory. Neotroprical Entomology 2005 34(5): 815-822.

[38] Ridgway RL, Siverstein RM, Inscoe MN., editors. Behaviour-modifying chemical for insect management. New York: Marcel Dekker; 1990.

[39] Schmera D, Guerin PM. Plant volatile compounds shorten reaction time and enhance attraction of the codling moth (Cydia pomonella) to codlemone. Pest Management Science 2012; 68(3): 454-461.

[40] Steiner LF. Methyl eugenol as an attractant for oriental fruit ßy. Journal of Economy Entomology 1952; 45: 241-248. 
[41] Stelinski LL, Lapointe SL, Meyer WL. Season-long mating disruption of citrus leafminer, Phyllocnistis citrella Stainton, with an emulsified wax formulation of pheromone. Journal of Applied Entomology 2010; 134: 512-520.

[42] Stelinski LL, Miller JR, Ledebuhr R, Siegert P, Gut LJ. Season-long mating disruption of Grapholita molesta (Lepidoptera: Tortricidae) by one machine application of pheromone in wax drops (SPLAT-OFM). Journal of Pest Science 2007; 80:109-117

[43] Tumlinson JH., Mitchell ER, Teal PEA, Heath RR, Mengelkoch LJ. Sex pheromone of fall armyworm, Spodoptera frugiperda (J.E. Smith), identification of components critical to attraction in the field. Journal of Chemical Ecology 1986; 12 (9): 1909-1926.

[44] Vargas RI, Piñero JC, Mau RFL, Stark JD, Hertlein M, Mafra-Neto A, Coler R, Getchell A. Attraction and mortality of oriental fruit flies to SPLAT-MAT-methyl eugenol with spinosad. Entomologia Experimentalis et Applicata 2009; 131(3): 286-293,

[45] Vargas RI, Stark JD, Hertlein M, Mafra Neto A, Coler R, Piñero JC. Evaluation of splat with spinosad and methyl eugenol or cue-lure for "attract-and-kill" of Oriental and Melon Fruit Flies (Diptera: Tephritidae) in Hawaii. Journal of Economic Entomology 2008; .101(3)759-768.

[46] Vilela EF, Della Lucia, TMC., editors. Feromônios de insetos: biologia, química e emprego no manejo de pragas. Editoras Holos; 2001.

[47] Willson HR, Trammel K. Sex pheromone trapping for control of codling moth, oriental fruit moth, lesser appleworm, and three tortricid leafrollers in New York apple orchard. Journal of Economy Entomology 1980; 73(2): 291-295.

[48] Witzgall P, Stelinski L, Gut L, Thomson D. Codling moth management and chemical ecology. Annual Review of Entomology 2008; 53: 503-522.

[49] Wyatt TD. Putting pheromones to work: Paths forward for direct control. pp. 445-459 In Cardé RT, Minks AK., editores. Insect Pheromone Research New Directions. New York: Chapman \& Hall; 1998.

[50] Youm O, Maliki Y, Hall DH, Farmanc DI, Foster JE. Pheromone-mediated mating disruption in the millet stem borer, Coniesta ignefusalis (Lepidoptera: Pyralidae). Crop Protection 2012 31(1): 50-57.

[51] Zanardi OZ. Biologia de Ceratitis capitata (Wiedemann, 1824) (Diptera: Tephritidae) em frutos de caquizeiro, macieira e videira e efeito de iscas tóxicas para o seu controle e sobre o parasitoide Diachasmimorpha longicaudata (Ashmead, 1905) (Hymenoptera: Braconidae) em laboratório. Phd thesis. Universidade Federal de Pelotas Brasil; 2011. 